\title{
Bone Conduction Stimulated VEMP Using the B250 Transducer
}

\author{
Karl-Johan Fredén Jansson (ID) \\ Bo Håkansson (iD) \\ Sabine Reinfeldt (iD) \\ Ann-Charlotte Persson (iD) ${ }^{2}$ \\ Måns Eeg-Olofsson (iD ${ }^{2}$ \\ 'Department of Electrical Engineering, \\ Chalmers University of Technology, \\ Gothenburg, Sweden; ${ }^{2}$ Department of \\ Otolaryngology, Head and Neck Surgery, \\ Sahlgrenska Academy, University of \\ Gothenburg, Gothenburg, Sweden
}

Correspondence: Karl-Johan Fredén Jansson

Department of Electrical Engineering, Chalmers University of Technology,

Gothenburg, 4I296, Sweden

Tel +463I 772 I783

Email karljohf@chalmers.se
Objective: Bone conduction (BC) stimulation is rarely used for clinical testing of vestibular evoked myogenic potentials (VEMPs) due to the limitations of conventional stimulation alternatives. The aim of this study is to compare VEMP using the new B250 transducer with the Minishaker and air conduction (AC) stimulation.

Methods: Thirty normal subjects between 20 and 37 years old and equal gender distribution were recruited, 15 for ocular VEMP and 15 for cervical VEMP. Four stimulation conditions were compared: B250 on the mastoid $\left(\mathrm{F}_{\mathrm{M}}\right)$; Minishaker and B250 on the forehead $\left(\mathrm{F}_{\mathrm{Z}}\right)$; and AC stimulation using an insert earphone.

Results: It was found that $\mathrm{B} 250$ at $\mathrm{F}_{\mathrm{M}}$ required a statistically significant lower hearing level than with AC stimulation, in average $41 \mathrm{~dB}$ and $35 \mathrm{~dB}$ lower for ocular VEMP and cervical VEMP, respectively, but gave longer $\mathrm{n} 10(1.1 \mathrm{~ms})$ and $\mathrm{n} 23(1.6 \mathrm{~ms})$. No statistical difference was found between $\mathrm{B} 250$ at $\mathrm{F}_{\mathrm{M}}$ and Minishaker at $\mathrm{F}_{\mathrm{Z}}$.

Conclusion: VEMP stimulated with $\mathrm{B} 250$ at $\mathrm{F}_{\mathrm{M}}$ gave similar response as the Minishaker at $\mathrm{F}_{Z}$ and for a much lower hearing level than $\mathrm{AC}$ stimulation using insert earphones.

Keywords: bone conduction, vestibular evoked myogenic potential, B250

\section{Introduction}

Vestibular evoked myogenic potential (VEMP) is an electro-physiological test procedure in the field of vestibular diagnostics, used for objective testing of the otolith organs (utriculus and sacculus) of the vestibular system. VEMP has shown to be an efficient compliment to the conventional methods, such as caloric and head impulse tests, and is used for diagnosis of almost any peripheral vestibular disorder including superior semicircular dehiscence syndrome, vestibular Schwannoma and Meniere's disease. ${ }^{1-3}$ The procedure to perform VEMP requires specific experience and the method has been developed over time. A short summary will follow, but for a recent extensive overview of methods, pitfalls and clinical applications, see Rosengren et al $2019 .^{4}$

In VEMP testing, the vestibular system can be stimulated by both air conduction (AC) sound and bone conduction (BC) vibration, like the auditory part of the ear, but with tone bursts and clicks instead of pure or warble tones. ${ }^{5}$ At a certain sound or vibration level, a short stimulus will activate a muscular reflex, originating from the vestibular organ. The muscular response can be recorded by surface electrodes on the sternocleidomastoideus (SCM) muscle (cervical- or cVEMP) and on the inferior oblique muscle beneath the eye (ocular- or oVEMP), first described by Colebatch and Halmagyi $1992 .^{6}$ In practice, the stimulus can be applied via AC using insert earphones or via $\mathrm{BC}$ using a vibrating transducer, a tendon hammer or 
an electro-mechanic impact device. ${ }^{4,7-10}$ A drawback with $\mathrm{AC}$ stimulation is the hazardous high sound levels required to evoke an oVEMP response, ${ }^{11,12}$ while $\mathrm{BC}$ can be successfully used at considerably lower and for the cochlea safer levels. ${ }^{13}$ Also, BC stimulation is advantageous in patients with conductive hearing loss as the mechanical vibrations induced in the skull bone can by-pass any obstruction in the outer or the middle ear. ${ }^{4}$ Even though there are potential advantages with BC stimulated VEMP, it is rarely used in clinical settings since today's transducers are either not powerful enough or impractical to use. Audiometric transducers, such as Radioear B71 and B81 (Interacoustics A/S, Assens, Denmark) are easy to use, but have limited output power and generate too much harmonic distortion at $250 \mathrm{~Hz} \cdot{ }^{13-17}$ Murofushi et al and Handzel and Himmelfarb have shown that occlusion can be used to increase the cVEMP and oVEMP response when using B81. ${ }^{18,19}$ Another option for BC stimulated VEMP is to use the Minishaker B\&K4810 (Brüel \& Kjær, Denmark). Even though the Minishaker is powerful enough for VEMP, it requires an additional power amplifier and is not optimal for clinical use as it needs to be handheld due to its weight and size. Recently, a new BC transducer called B250 (Figure 1) was introduced for BC stimulated VEMP (prototypes manufactured by Ortofon A/S, Nakskov, Denmark). The B250 generates high output power with low distortion at $250 \mathrm{~Hz}$ and can evoke clinical viable BC-VEMP responses at relatively low stimulation level (Håkansson et al 2018). For comparison, the Minishaker weighs $1.1 \mathrm{~kg}$ which is about 13.8 times more than the B250 which weighs only 80 grams. Also, the B250 is about 30 times smaller in size and can easily be attached to the mastoid by using a standard steel spring head band, see Figure 1. The Minishaker is more commonly placed on the forehead and being handheld because of its size and weight. However, forehead stimulation can evoke symmetrical and bilateral VEMP responses from both vestibular organs simultaneously, but not all VEMP platforms support bilateral recordings which requires five electrodes. Also, it is difficult to attain a sufficient EMG signal from both SCM muscles simultaneously in cVEMP. When using a steel spring head band with B250, the mastoid position would be more comfortable and practical in the clinical setting as it is more like the procedure of using AC stimulated VEMP or ordinary BC audiometry, where each side is measured separately. Following the positive outcomes in the first pilot study using B250, presented by Håkansson et al $2018,{ }^{13}$ we now aim to investigate the VEMP responses on a larger group of normal subjects using B250 at the mastoid position and compare the results with the Minishaker on the forehead, and $\mathrm{AC}$ stimulation.

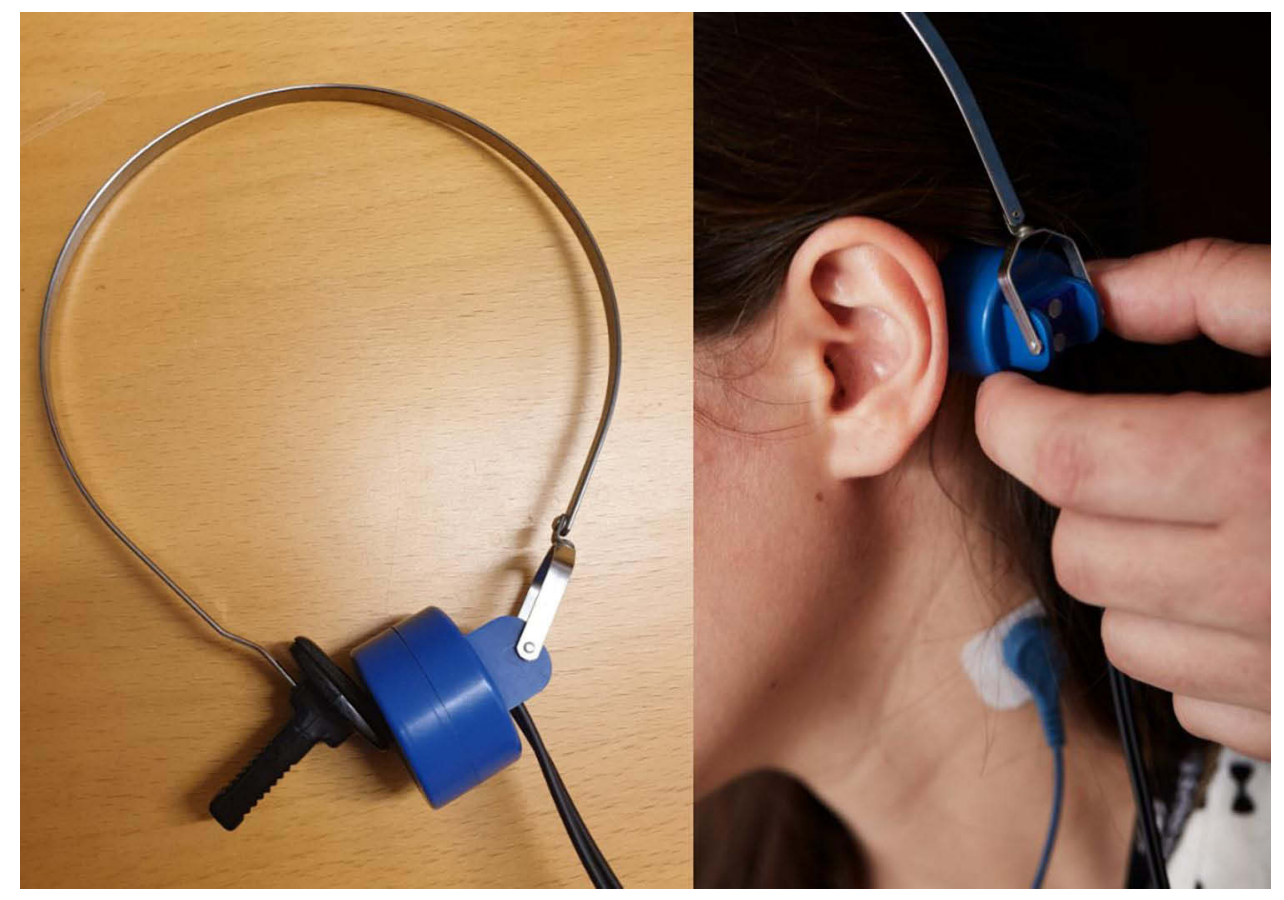

Figure I The B250 transducer appearance and how it is attached to the mastoid with a steel spring headband prior to cVEMP testing. 


\section{Aim of Study}

The overall aim of this study was to measure VEMP responses using the B250 transducer placed on the mastoid on a group of normal subjects and to compare the results with both $\mathrm{AC}$ stimulation using insert earphones and forehead $\mathrm{BC}$ stimulation using the Minishaker.

In more detail, one sub-aim is to extract normative VEMP data explicitly for the B250. A second sub aim is to compare the data obtained with $\mathrm{B} 250$ on the mastoid with the data obtained with $\mathrm{AC}$ stimulation and Minishaker on the forehead, which are assumed to be the present standards for cVEMP and oVEMP, respectively. A final sub-aim is to compare the B250 with the Minishaker applied in the same position, ie at the forehead.

\section{Methods}

Regarding the procedures for both cVEMP and oVEMP measurements, the recommendations as described by Rosengren et al 2019 are followed. ${ }^{4}$

\section{Subjects}

In total 30 volunteers, considered to have normal vestibular and hearing function, of ages 20-37 years old and of equal gender distribution, participated in the study and were divided into two groups where 15 subjects were tested for oVEMP (8m, 7f) and 15 subjects for cVEMP $(7 \mathrm{~m}, 8 \mathrm{f})$. Average age was 28 years $(21-33$ years) in the oVEMP group and 27 years (20-37 years) in the cVEMP group. To save time and complete the investigation for each subject during one session, only one vestibular organ was tested per subject. The recruitment of these subjects was made consecutively after an announcement at our University with inclusion of "normal" subjects. The inclusion criteria being "normal" was based on normal hearing thresholds (better than $20 \mathrm{~dB} \mathrm{HL}$ (hearing level) at all frequencies tested) and that they confirmed not having any experience of vertigo episodes or previous hearing problems. Audiograms were measured before VEMPtesting comprising both $\mathrm{AC}$ and $\mathrm{BC}$ tone thresholds at audiometric standard frequencies between 250 and 8000 $\mathrm{Hz}$ using an $\mathrm{AC} 40$ audiometer from Interacoustics $\mathrm{A} / \mathrm{S}$ (Assens, Denmark). This clinical study was approved by the Regional ethical review board in Gothenburg (537-18) and performed in accordance with the declaration of Helsinki. All participants signed a written informed consent before entering the study.

\section{Stimulation}

$\mathrm{AC}$ sound is naturally side-specific, while $\mathrm{BC}$ vibrations induced in the skull bone give bilateral cochlear stimulation. ${ }^{20}$ Therefore, the AC sound was applied only to the ear-canal ipsilateral to the vestibular organ under test, while the BC stimulation with B250 was applied both from ipsilateral mastoid $\left(\mathrm{F}_{\mathrm{M}}\right)$ and from the forehead midline position $\left(\mathrm{F}_{\mathrm{Z}}\right)$ just below the hairline. The Minishaker was only used on the forehead as it required to be handheld and applied with a static force of approximately $10-12 \mathrm{~N}$, created by its own weight. To ensure the same size of the area attached to the skin for both B250 and Minishaker, a specially designed adapter was connected to the Minishaker, see Figure 2. The adaptor had a circular and slightly concave surface with a diameter of $30 \mathrm{~mm}$, designed to replicate the shape of the B250 surface attached to the skin. Also, the B250 transducer was applied with a static force of approximately $10 \mathrm{~N}$, using a steel spring headband P-3333 (Brüel \& Kjær) when attached to the mastoid, and with an elastic head band when applied to the forehead. Normally, P-3333 is assumed to give 5-6 N static force according to the audiometric standard $(5.4 \mathrm{~N})$, but by the attachment to the $\mathrm{B} 250$, which has a more protruding housing compared to B71/B81, some extra 4-5 N will be applied to the skin surface, ie in total approximately $10 \mathrm{~N}$.

For AC stimulated VEMP, the most clinically used frequency for VEMP is $500 \mathrm{~Hz}$. For BC-VEMP, Welgampola et al and Chihara et al have shown that tone burst stimulation at $250 \mathrm{~Hz}$ is more efficient than at $500 \mathrm{~Hz},{ }^{21,22}$ which was further confirmed using B250 in Håkansson et al. ${ }^{13}$

Some studies suggest that BC-VEMP can be efficiently evoked at frequencies even lower than $250 \mathrm{~Hz},{ }^{23,24}$ but then the risk of involving response peaks without vestibular origin is increased. Rosengren et al recommended the stimulus duration not to exceed $6 \mathrm{~ms}$, which otherwise may have a negative effect on the response in terms of decreased amplitudes and prolonged latencies. ${ }^{4}$ With respect to stimulus duration, 1-cycle stimulus at $250 \mathrm{~Hz}$, which corresponds to a duration of $4 \mathrm{~ms}$, was assumed to be more appropriate than $125 \mathrm{~Hz}$, ie a duration of $8 \mathrm{~ms}$ duration. Therefore, to achieve a fair comparison between the $\mathrm{AC}$ and the $\mathrm{BC}$ stimuli, a 2-cycle tone burst at $500 \mathrm{~Hz}$ was chosen for $\mathrm{AC}$ and a 1-cycle tone burst at $250 \mathrm{~Hz}$ was chosen for $\mathrm{BC}$, resulting in a $4 \mathrm{~ms}$ long duration for both stimuli.

BC-VEMP response is known to depend on the stimulation signal polarity and position on the skull. When the 


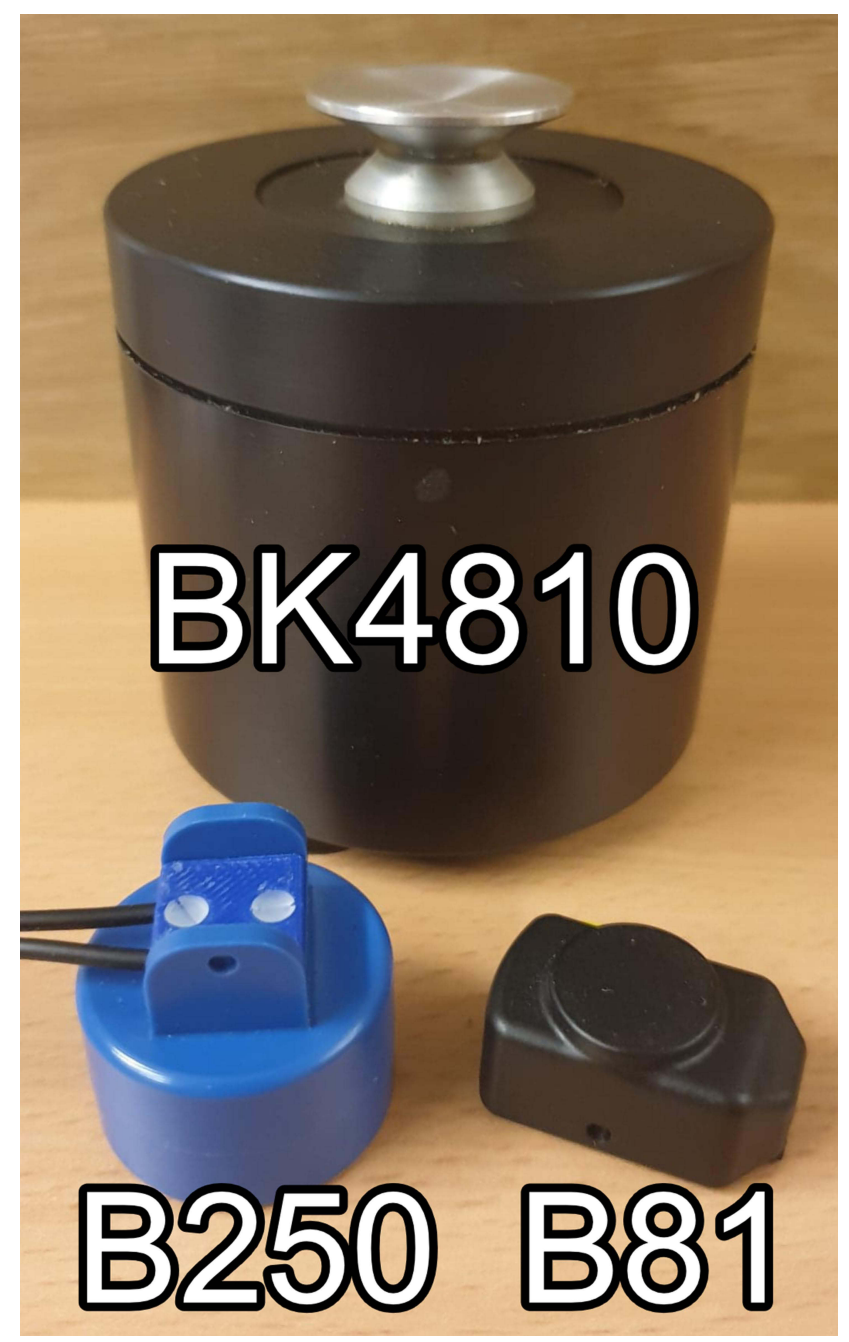

Figure 2 The transducers B250, Radioear B8I and the Minishaker (BK48I0) showing their appearances and size differences. An adapter with the same shape as the B250 surface touching the skin is attached to the Minishaker.

signal polarity for the first half period is set to generate a force towards the head, it is referred to as "positive" (condensation), and when it is inverted and outwards, it is referred to as "negative" (rarefaction). For oVEMP, which is most critical in terms of low amplitudes, a positive polarity is known to be most efficient for the forehead stimulation, while negative polarity gives higher amplitudes for the ipsilateral mastoid stimulation. ${ }^{9}$ The same polarity dependence was confirmed in a pre-test performed with the B250 at $250 \mathrm{~Hz}$, and therefore in this study, the forehead stimuli was always applied with positive polarity and the mastoid stimuli with negative polarity, see Figure 3 for the different electrical source signals. According to Westin and Brantberg (2014), using $125 \mathrm{~Hz}$ gives a delay of 3-4 $\mathrm{ms}$ in the oVEMP latencies, but that was not obvious at $250 \mathrm{~Hz}$ in our pre-testing. ${ }^{9}$ It should be mentioned that the actual mechanical stimulation signal from BC transducers will not exactly follow the shape of the electrical stimulation signal due to ramp up and ringing effects. Therefore, all ramp up delays were calibrated for, and the ringing amplitude was verified to be significantly decreased after 6-8 ms avoiding overlapping of the VEMP response.

All VEMP measurements were performed with the Eclipse system from Interacoustics $\mathrm{A} / \mathrm{S}$ (Assens, Denmark). The B250 was able to generate an output force level up to $150 \mathrm{~dB}$ rms FL re $1 \mu \mathrm{N}$ at $250 \mathrm{~Hz}$ when driven directly connected to the Eclipse output, verified by an artificial mastoid B\&K4930. As the B250 has similar electrical impedance as audiometric transducers the B71/B81 (approximately $4 \mathrm{ohm}$ DC), it does not require any additional power amplifier to achieve its maximum output levels.

\section{Calibration of BC Devices Using the Artificial Mastoid B\&K4930}

To calibrate each $\mathrm{BC}$ device around $250 \mathrm{~Hz}$, first the artificial mastoid B\&K4930 had to be calibrated, including adjustment for the different adaptor surfaces of the B71/B81 (flat
AC:

2-cycle tone burst@ $500 \mathrm{~Hz}$

Polarity: Positive

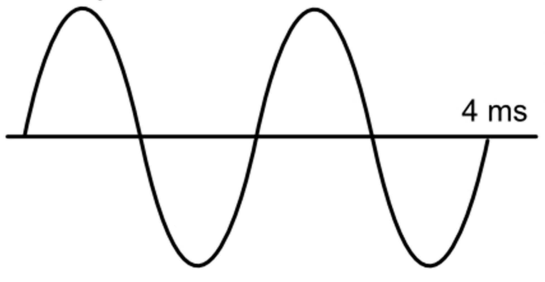

I $\mathrm{B250} \mathrm{F}_{\mathrm{M}}$ :

I 1-cycle tone burst@ $250 \mathrm{~Hz}$

I Polarity: Negative

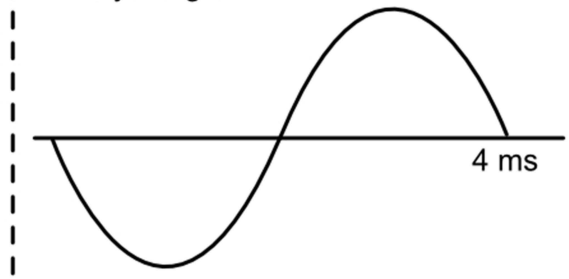

I BK4810 \& B250 $\mathrm{F}_{\mathrm{z}}$ :

I-cycle tone burst@ $250 \mathrm{~Hz}$

I Polarity: Positive

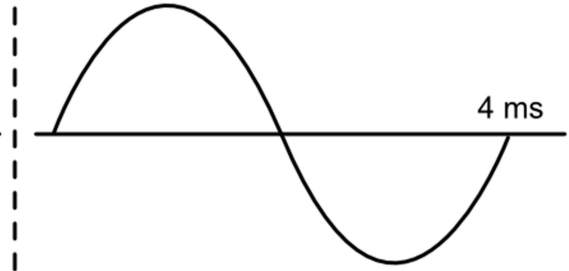

Figure 3 The 4 milliseconds $(\mathrm{ms})$ long electrical tone burst signal for generating, from left to right, air conduction ( $A C)$ stimuli with insert earphone, bone conduction (BC) stimuli with $\mathrm{B} 250$ on the mastoid $\left(\mathrm{F}_{\mathrm{M}}\right)$ and $\mathrm{BC}$ stimuli with $\mathrm{B} 250$ and Minishaker on the forehead $\left(\mathrm{F}_{\mathrm{Z}}\right)$. 
$1.75 \mathrm{~cm}^{2}$ ) and the B250 (concave $7.10 \mathrm{~cm}^{2}$ ). It was found that the calibration factor at $250 \mathrm{~Hz}$ was the same for both surfaces and differences were only seen for frequencies above $1 \mathrm{kHz}$. The curves in Figure 4 were then used when the frequency responses in Figure 5 were measured.

Figure 5 shows the frequency responses of all transducers measured on a calibrated artificial mastoid B\&K4930 over the frequency range $100-10,000 \mathrm{~Hz}$ when the input is normalized to 1 Volt. The driving signal voltage to the
Minishaker was amplified by $20 \mathrm{~dB}$ using an external power amplifier (LPA01 Laboratory Power Amplifier, Newtons4th Ltd., UK) to generate the same force levels as the B250. The maximum intensity of the AC stimuli was in this study limited to $129 \mathrm{~dB}$ peak SPL for the tone bursts to avoid hazardous sound levels.

The B81 is anticipated to be the new standard audiometric transducer for $\mathrm{BC}$ hearing testing and comprises a transducer of balanced electromagnetic separation

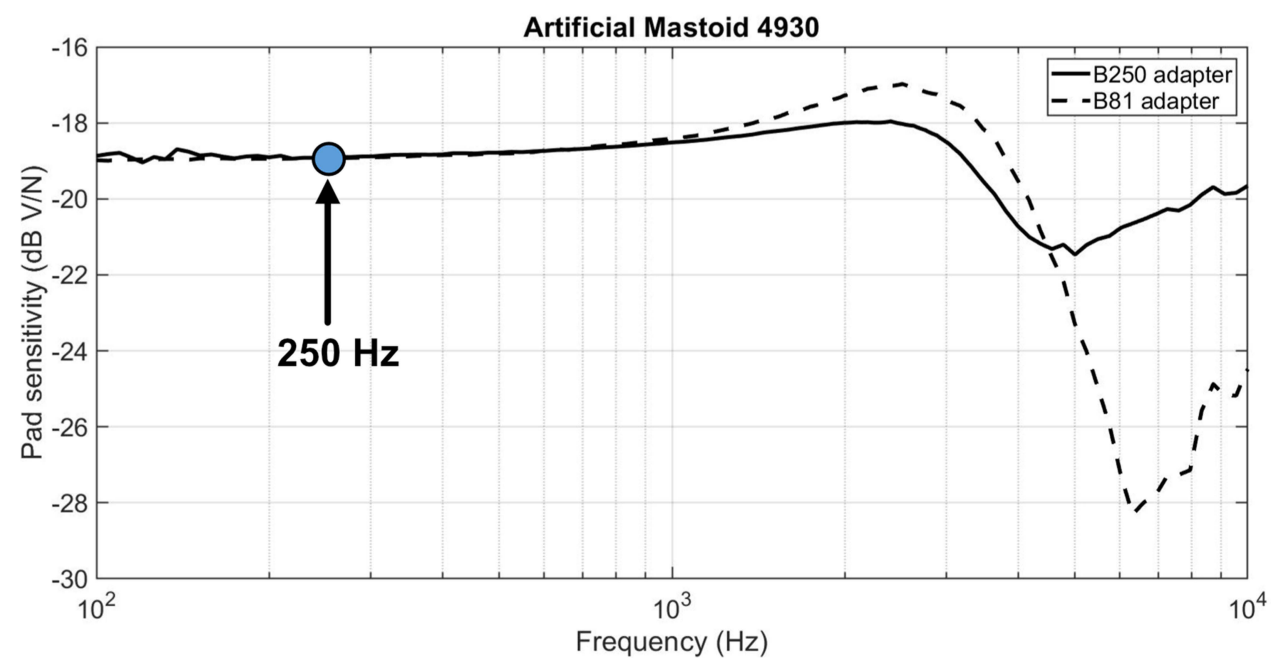

Figure 4 The pad correction curves for the artificial mastoid B\&K4930 when using B250 (solid line) and B8I (dashed line). Notice that the curves have the same value at $250 \mathrm{~Hz}$ (blue circle).

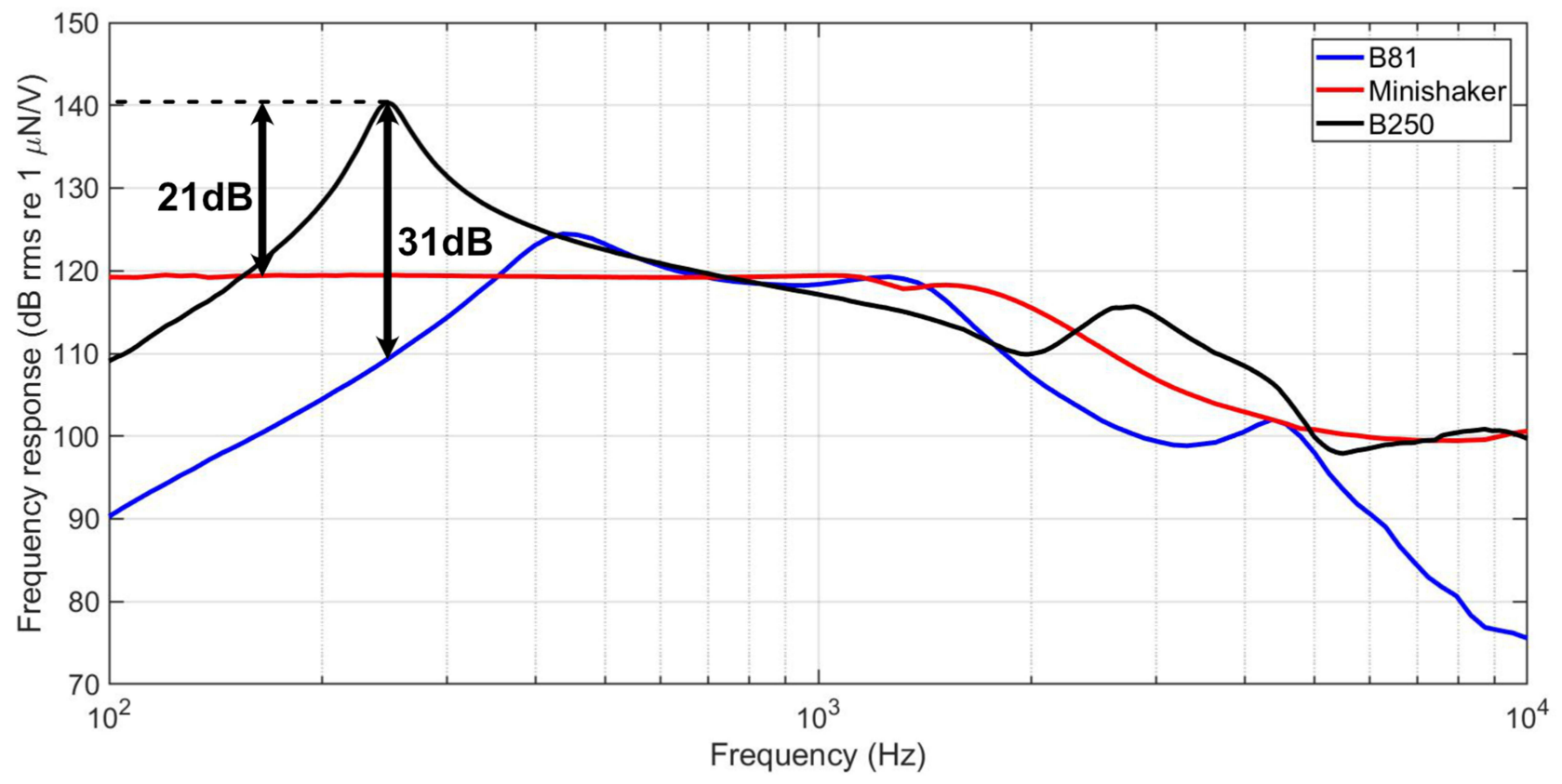

Figure 5 The frequency response in units of decibel root mean square relative I micro newton per volt (dB rms re I $\mu$ N/V) for B250 (black), Minishaker (red) and Radioear $\mathrm{B} 8 \mathrm{I}$ (blue) between 100 and $10000 \mathrm{~Hz}$ normalized to $\mathrm{I} \mathrm{V}_{\text {rms }}$ input voltage. The $3 \mathrm{I} \mathrm{dB}$ difference at $250 \mathrm{~Hz}$ between B250 and Radioear B8I is highlighted. 
transducer (BEST) type, ${ }^{14}$ which allows for higher output levels and reduced distortion in the lower audiometric frequency range. Even if B81 is a great improvement for audiometry, the $250 \mathrm{~Hz}$ tone burst will be significantly distorted at the level required to evoke a proper VEMP response, ie harmonics at $500 \mathrm{~Hz}$ and higher multiples of $250 \mathrm{~Hz}$ will be superimposed. ${ }^{15}$ Also, at $250 \mathrm{~Hz}$ where the B250 has its resonance frequency, the output level of the $\mathrm{B} 81$ is $31 \mathrm{~dB}$ lower for the same input voltage, see Figure 5. Therefore, the output of B81 is not sufficient for consistent VEMP measurements at this frequency with the voltage available from Eclipse. ${ }^{13}$ For these reasons, the B250 and the Minishaker were the only BC devices used in this study and B81 was disregarded.

\section{Recordings}

All VEMP parameters were extracted from the responses obtained at a fixed super threshold stimulation level, which was $140 \mathrm{~dB}$ peak FL (65 dB nHL) for BC-VEMP and 124 $\mathrm{dB}$ peak SPL (100 dB nHL) for AC-VEMP. Both levels were chosen as approximately the middle between the average oVEMP thresholds and the maximum used stimulation intensity. The VEMP threshold was defined by the lowest stimulation level where a clear biphasic VEMP response appeared and the maximum stimulation intensity was $75 \mathrm{~dB}$ nHL (150 dB peak FL) for BC and $105 \mathrm{~dB}$ nHL for $\mathrm{AC}$ (129 dB peak SPL). One balance organ per subject was tested for both AC- and BC-VEMP and was chosen as the side with the best $\mathrm{AC}$ threshold at $500 \mathrm{~Hz}$. In subjects with equal $\mathrm{AC}$ thresholds on both ears, the test side was chosen to obtain an equal left-right side distribution among the tested subjects. The recordings were bandpass filtered from 10 to $1000 \mathrm{~Hz}$ and recorded with a sample rate of $3000 \mathrm{~Hz}$. The stimulation signal was applied at a repetition rate of $8 \mathrm{~Hz}$ with 100 recordings for oVEMP and 100-200 recordings for cVEMP, depending on how quickly the waveform was stabilized.

In the cVEMP measurements, the signal electrode was attached $1 \mathrm{~cm}$ above the mid portion of the ipsilateral SCM. The reference electrode was attached on the upper sternum and the ground electrode on the midline of the forehead. In cVEMP, the SCM muscle must be under tension in order to measure the inhibitory reflex. In this study, this was done by turning and slightly tilting the head away from the stimuli side. During the whole cVEMP procedure, electromyography (EMG) control was used where the patient was asked to keep the EMG signal within 80 to $140 \mu \mathrm{V}$ to reduce its influence on the cVEMP response. Furthermore, all cVEMP recordings were normalized in amplitude using the EMG scaling function in the Eclipse software.

In the oVEMP testing, the signal electrode was attached beneath the contralateral eye, as it is a sidecrossing reflex, in order to measure the excitation response from the inferior oblique muscle of the eye. ${ }^{4}$ In this study, the signal electrode was placed just below the eyelid and vertically in line with the pupil, whereas the center of the reference electrode was placed approximately $2 \mathrm{~cm}$ below the center of the signal electrode and the ground electrode was placed on the upper part of the sternum. With these electrode attachments for cVEMP and oVEMP, a negative peak corresponds to muscle relaxation (p15-oVEMP, p13 c-VEMP) and a positive peak corresponds to muscle contraction (n10-oVEMP, n23-cVEMP).

The investigational parameters extracted from the VEMP waveforms were time instances (latencies) for the biphasic contraction/relaxation peaks, amplitudes of these peaks, and stimulation level at the VEMP response threshold. Whereas the peak parameters were extracted at supra threshold levels, the response threshold was determined using $5 \mathrm{~dB}$ steps with descending intensity and defined as the lowest stimulation intensity where the bi-phasic peak-to-peak amplitude is greater than the background noise. In clinical practice, when investigating patients with a possible vestibular disorder, the asymmetry ratio is often of more interest than the amplitudes but does not add to the evaluation of different transducers. Asymmetry ratio is more related to individual differences between both sides rather than the stimulation modality being used, which motivates the evaluation of only one side per subject in this study.

\section{Hearing Level Correction}

The threshold is presented in units of normalized hearing level $(\mathrm{dB} n \mathrm{~nL})$, which is defined as the $\mathrm{dB}$ HL value corrected for the reduced perceived loudness when a stimulus becomes shortened in time even if the amplitude is fixed. The corrections from $\mathrm{dB}$ SPL/FL to $\mathrm{dB} \mathrm{nHL}$ are incorporated in the Eclipse software for a "ramp upplateau-ramp down" proportion of "2-1-2" tone bursts. For $\mathrm{BC}$ at $250 \mathrm{~Hz}$ and $\mathrm{AC}$ at $500 \mathrm{~Hz}$, the correction is preprogrammed to $74.5 \mathrm{~dB}$ and $23.5 \mathrm{~dB}$, respectively.

It should also be noted that the tone bursts of this study have a different "ramp up-plateau-ramp down" proportion, ie is following " $0-1-0$ " for BC and " $0-2-0$ " for AC. This gives a total stimuli length of $4 \mathrm{~ms}$, which is shorter than the "2-1-2" stimulation length of 10 and $20 \mathrm{~ms}$ for 500 and 250 
$\mathrm{Hz}$, respectively. In other words, a "2-1-2" tone burst might be perceived either louder than or equal to the "0-1-0" and "0-2-0" tone bursts. In this study, it was decided to keep the pre-programmed correction values also for the shorter tone bursts in order to include a margin of safety to our comparison between $\mathrm{AC}$ and $\mathrm{BC}$ in $\mathrm{dB} \mathrm{nHL}$.

\section{Statistics}

Based on a power analysis, it was found that at least 13 subjects were needed to show possible statistically significant difference between $\mathrm{AC}$ and $\mathrm{BC}$ stimulation hearing level to reach VEMP thresholds.

For the different simulation alternatives, VEMP latencies and amplitudes, as well as stimulation hearing levels, are analyzed by means and standard deviations (SD), and significance is tested using the $t$-test for "paired two sample for means". A probability value of $p<0.05$ was considered for rejecting the null hypothesis, ie that there is a statistically significant difference.

\section{Results}

In all 30 subjects, clear cVEMP and oVEMP responses were measured and all parameters could be extracted in all stimulation modalities, comprising $\mathrm{B} 250$ on the mastoid $\left(\mathrm{F}_{\mathrm{M}}\right)$, Minishaker and $\mathrm{B} 250$ on the forehead $\left(\mathrm{F}_{\mathrm{Z}}\right)$, and $\mathrm{AC}$ stimulation using an insert earphone. A typical oVEMP and cVEMP response is shown in Figures 6 and 7, respectively, for B250 at the mastoid and AC via earphones. The latency and peak parameters were extracted at a target stimulation level of $65 \mathrm{~dB} \mathrm{nHL}$ for $\mathrm{BC}$ and at $100 \mathrm{~dB} \mathrm{nHL}$ for $\mathrm{AC}$, see Figures 6 and 7. In five of the subjects, the AC-oVEMP parameters had to be extracted at $105 \mathrm{~dB} \mathrm{nHL}$ as they had thresholds above $95 \mathrm{~dB} \mathrm{nHL}$. The threshold was defined as the lowest $\mathrm{dB}$ nHL stimulus where a VEMP response could be identified. All latencies and the stimulation levels at threshold are presented in Figure 8 for each subject, while numerical mean values with SDs and VEMP amplitudes are summarized in Table 1.

As can be seen in Figure 8 and in Table 1, all stimulation modalities seem to give very similar latencies for both cVEMP and oVEMP. All latencies were statistically tested for the null hypothesis, ie that there is no difference with reference to $\mathrm{B} 250 \mathrm{~F}_{\mathrm{M}}$ stimulation, and the corresponding $\mathrm{p}$ values are inserted in Table 1. It seems that the latencies for oVEMP using the B250 at the mastoid are not statistically different except when compared with AC stimuli$\mathrm{n} 10(\mathrm{p}=0.0023)$ and $\mathrm{B} 250 \mathrm{~F}_{\mathrm{Z}}-\mathrm{n} 10(\mathrm{p}=0.030)$ where the null hypothesis is rejected. For cVEMP, the latency differences are not statistically different, except for AC stimuli$\mathrm{n} 23 \quad(\mathrm{p}=0.0014)$ and $\mathrm{B} 250 \quad \mathrm{~F}_{Z}-\mathrm{p} 13 \quad(\mathrm{p}=0.022)$. Interestingly, there is no statistical difference in latencies when comparing the B250 at the mastoid with the Minishaker at the forehead, neither for cVEMP nor for oVEMP $(p>0.05)$.

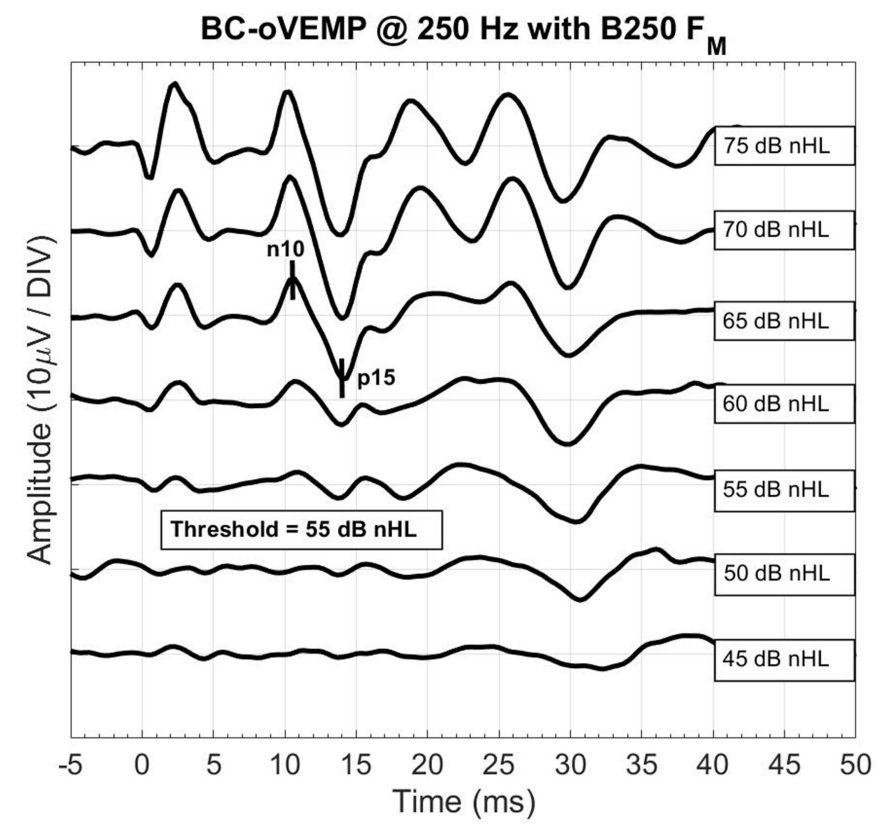

Figure 6 Typical clinically viable BC-oVEMP (left) on the mastoid $F_{M}$ at $250 \mathrm{~Hz}$ and AC-oVEMP (right) at $500 \mathrm{~Hz}$ for different levels with the $\mathrm{nI} 0$ and $\mathrm{PI} 5$ peaks marked. Parameters were extracted at 65 and $100 \mathrm{~dB} \mathrm{nHL}$ and threshold at lowest level where VEMP response was detected. 

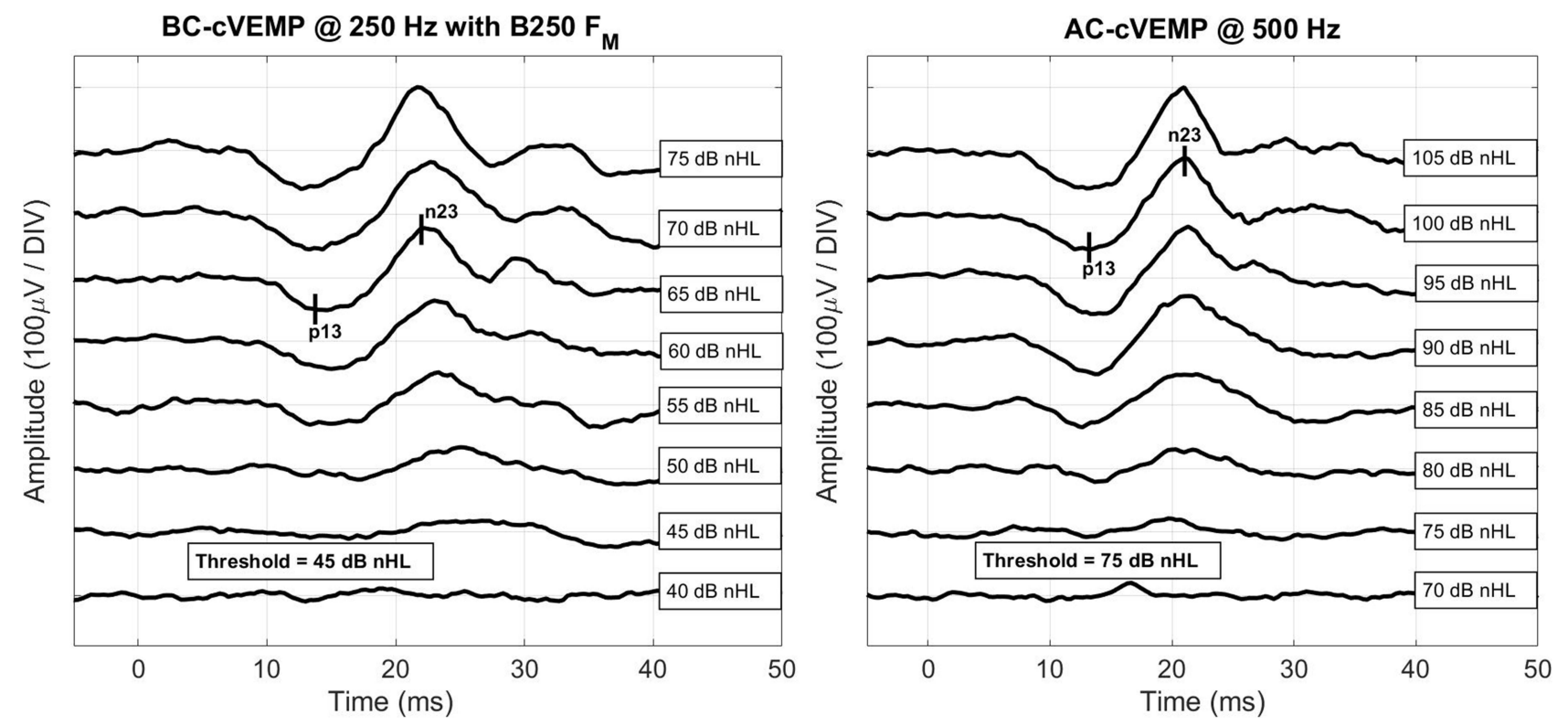

Figure 7 Typical clinically viable BC-cVEMP (left) on the mastoid $F_{M}$ at $250 \mathrm{~Hz}$ and AC-cVEMP (right) at $500 \mathrm{~Hz}$ for different levels with the p/3 and n23 peaks marked. Parameters were extracted at 65 and $100 \mathrm{~dB} \mathrm{nHL}$ and threshold at lowest level where VEMP response was detected.
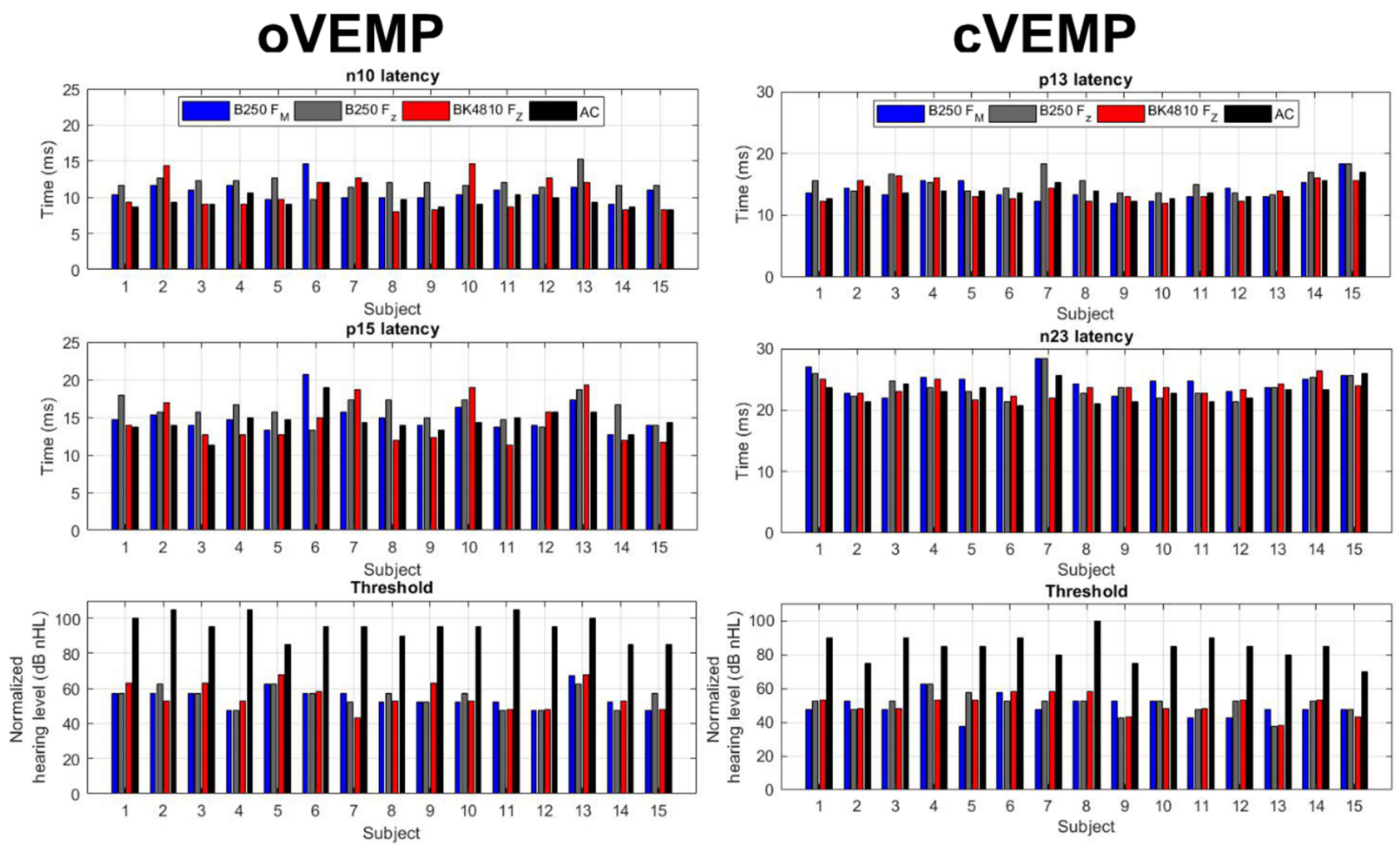

Figure 8 The individual oVEMP and cVEMP latencies obtained at $65 \mathrm{~dB} n \mathrm{~nL}$ for BC-VEMP and $100 \mathrm{~dB} \mathrm{nHL}$ for AC-VEMP for each subject using B250 on the mastoid ( $\mathrm{F}_{\mathrm{M}}$ in blue), $B 250$ on the forehead ( $F_{Z}$ in grey), the Minishaker BK4810 on the forehead ( $F_{Z}$ in red) and insert earphones ( $A C$ in black). The shown parameters are latency times in milliseconds (ms) for $\mathrm{nIO}$ and pI5 (oVEMP) and pl3 and n23 (cVEMP), and the lowest panels show the stimulation level in dB nHL at the VEMP thresholds. 
Table I Numerical Means and Standard Deviations for oVEMP and cVEMP Latencies (n I0, pI5, pl3, n23) and Thresholds Using B250 at Mastoid $\left(F_{M}\right)$ and Forehead $\left(F_{Z}\right)$, Minishaker B\&K48IO at $F_{Z}$ and Insert Earphone for All Subjects $(N)$

\begin{tabular}{|c|c|c|c|c|c|c|}
\hline & Parameter & B250 $F_{M}$ & $\mathrm{~B} 250 \mathrm{~F}_{\mathrm{Z}}$ & $B \& K 48 I 0 F_{Z}$ & Earphones & \\
\hline \multirow{8}{*}{$\begin{array}{l}\text { OVEMP } \\
\mathrm{N}=15\end{array}$} & \multirow[t]{2}{*}{ Amplitude nI0-pI5 } & \multirow[t]{2}{*}{$5.8 \pm 3.1$} & $5.4 \pm 3.0$ & $6.6 \pm 3.3$ & $4.6 \pm 3.6$ & \multirow[t]{2}{*}{$\mu \mathrm{V}$} \\
\hline & & & $\mathrm{p}=0.5 \mathrm{I} 4$ & $\mathrm{p}=0.382$ & $\mathrm{p}=0.34 \mathrm{I}$ & \\
\hline & \multirow[t]{2}{*}{ Latency n 10} & \multirow[t]{2}{*}{$10.8 \pm 1.3$} & $12.0 \pm 1.2$ & $10.5 \pm 2.3$ & $9.7 \pm 1.2$ & \multirow[t]{2}{*}{$\mathrm{ms}$} \\
\hline & & & $\mathrm{p}=0.030 *$ & $\mathrm{P}=0.59$ & $\mathrm{p}=0.0023^{*}$ & \\
\hline & \multirow[t]{2}{*}{ Latency pl5 } & \multirow[t]{2}{*}{$15.0 \pm 2.0$} & $16.0 \pm 1.6$ & $14.4 \pm 2.9$ & $14.5 \pm 1.7$ & \multirow[t]{2}{*}{$\mathrm{ms}$} \\
\hline & & & $p=0.17$ & $\mathrm{p}=0.34$ & $\mathrm{p}=0.13$ & \\
\hline & \multirow[t]{2}{*}{ Hearing level at threshold } & \multirow[t]{2}{*}{$54.6 \pm 5.6$} & $55.0 \pm 5.6$ & $55.7 \pm 7.8$ & $95.3 \pm 6.9$ & \multirow[t]{2}{*}{$\mathrm{dB} n \mathrm{~nL}$} \\
\hline & & & $\mathrm{P}=0.77$ & $\mathrm{p}=0.50$ & $\mathrm{p}=3.6 \cdot 10^{-11} *$ & \\
\hline \multirow{10}{*}{$\begin{array}{l}\text { cVEMP } \\
N=15\end{array}$} & \multirow[t]{2}{*}{ Amplitude n23-p/3 } & \multirow[t]{2}{*}{$122.8 \pm 38.6$} & $103.4 \pm 25.1$ & $|28.6 \pm 4| .3$ & $154.6 \pm 57.8$ & \multirow[t]{2}{*}{$\mu \mathrm{V}$} \\
\hline & & & $\mathrm{P}=0.046 *$ & $p=0.667$ & $p=0.037^{*}$ & \\
\hline & \multirow[t]{2}{*}{ Amplitude n23-p/3 } & \multirow[t]{2}{*}{$3.0 \pm 2.8$} & $2.4 \pm 2.0$ & $2.9 \pm 2.4$ & $1.5 \pm 0.6$ & \multirow[t]{2}{*}{ EMG scaled** } \\
\hline & & & $p=0.087$ & $\mathrm{p}=0.837$ & $\mathrm{p}=0.047^{*}$ & \\
\hline & \multirow[t]{2}{*}{ Latency pl3 } & \multirow[t]{2}{*}{$14.0 \pm 1.7$} & $15.3 \pm 1.7$ & $13.9 \pm 1.6$ & $14.0 \pm 1.3$ & \multirow[t]{2}{*}{$\mathrm{ms}$} \\
\hline & & & $p=0.022 *$ & $p=0.841$ & $p=0.895$ & \\
\hline & \multirow[t]{2}{*}{ Latency n23 } & \multirow[t]{2}{*}{$24.5 \pm 1.7$} & $23.8 \pm 1.9$ & $23.6 \pm 1.3$ & $22.9 \pm 1.6$ & \multirow[t]{2}{*}{$\mathrm{ms}$} \\
\hline & & & $\mathrm{P}=0.077$ & $\mathrm{p}=0.096$ & $\mathrm{p}=0.00144^{*}$ & \\
\hline & \multirow[t]{2}{*}{ Hearing level at threshold } & \multirow[t]{2}{*}{$49.0 \pm 6.2$} & $50.6 \pm 5.9$ & $50.3 \pm 5.9$ & $84.3 \pm 7.5$ & \multirow[t]{2}{*}{$\mathrm{dB} n \mathrm{~nL}$} \\
\hline & & & $p=0.42$ & $\mathrm{p}=0.52$ & $\mathrm{p}=1.0 \cdot 10^{-9} *$ & \\
\hline
\end{tabular}

Notes: The latencies and amplitudes were measured at $65 \mathrm{~dB} \mathrm{nHL}$ for $\mathrm{BC}$ stimulation and at $100 \mathrm{~dB} \mathrm{nHL}$ for $\mathrm{AC}$ stimulation. *Indicates a statistically significant difference with $\mathrm{p}<0.05$, and ${ }^{* *}$ where scaling was made by taking the amplitude $\mathrm{pl}-\mathrm{nI}$ (peak to peak) and dividing by the RMS of the EMG signal during the pre-stimulus period.

Regarding peak-to-peak amplitudes for oVEMP, the mean value of the B250 at the mastoid falls within the ranges (mean $\pm \mathrm{SD}$ ) of all the other test conditions, but for cVEMP there is a statistically significant, but small difference relative to $\mathrm{B} 250 \quad \mathrm{~F}_{\mathrm{Z}} \quad(\mathrm{p}=0.046)$ and $\mathrm{AC}$ $(p=0.037)$, see Table 1 . Notice how the statistically significant difference relative to $\mathrm{B} 250 \mathrm{~F}_{\mathrm{Z}}$ and $\mathrm{AC}$ disappears, respectively decrease $(\mathrm{p}=0.047)$, when EMG scaling is applied. This indicates that variations in SCM muscle tension may need to be compensated for to not cause any statistically significant difference in cVEMP amplitudes.

Regarding the stimuli level required to achieve the VEMP threshold response, the BC modality systematically required a lower level of sound than $\mathrm{AC}$ stimulation, which is shown in Figure 8 (lower panels). This decrease in perceived stimulation level in $\mathrm{dB} \mathrm{nHL}$, using $\mathrm{B} 250$ on the mastoid, was in comparison to $\mathrm{AC}$ stimulation highly statistically significant and on the average $40.7 \pm 8.6 \mathrm{~dB}$ $\left(p=3.6 \cdot 10^{-11}\right)$ for oVEMP and $35.4 \pm 9.6 \mathrm{~dB}\left(\mathrm{p}=1.0 \cdot 10^{-9}\right)$ for cVEMP.

\section{Discussion}

The most important result in this study is that the sound levels required for performing adequate $\mathrm{cVEMP}$ or oVEMP investigations are on the average $35 \mathrm{~dB}$ and $41 \mathrm{~dB}$ lower, respectively, when using a $250 \mathrm{~Hz}$ single sine cycle with the B250 transducer compared to AC stimulation with two cycles at $500 \mathrm{~Hz}$. This result is in line with Welgampola et al 2003 and McNerney and Burkard 2011, ${ }^{21,25}$ who pointed out this sensitivity advantage with $\mathrm{BC}$ vs AC stimuli, as well as in line with the first pilot study by Håkansson et al 2018 showing similar results using B250 in three subjects (32 and $39 \mathrm{~dB}$ for cVEMP and oVEMP, 
respectively). ${ }^{13}$ This shows that the advantage of $\mathrm{BC}$ stimulation being independent of an existing conductive hearing loss also should hold for B250. When earphones are used, the average AC stimulation level at threshold in oVEMP is as high as $118.8 \mathrm{~dB}$ peak SPL (the correction factor of 23.5 $\mathrm{dB}$ added to the $95.3 \mathrm{~dB}$ in Table 1). Recalling that in a typical VEMP investigation, the sound level should preferably be provided at a level $10-15 \mathrm{~dB}$ over the threshold, these sound impulses are in the range of $130-135 \mathrm{~dB}$ peak SPL. Therefore, AC stimulation is sometimes beyond a comfortable hearing level and close to hazardous levels for causing a hearing impairment. ${ }^{11,12,26}$

Under the assumption that the obtained VEMP responses with the B250 transducer activates the same nerve fibers in the otolithic organ (sacculus and utriculus) as the Minishaker stimuli on the forehead, these responses will give similar clinical information of the vestibular system. However, this study does not address that question, but studies indicate that cVEMP thresholds (sacculus) are normally lower than oVEMP thresholds (utriculus), for both $\mathrm{AC}$ and $\mathrm{BC}$ stimulation, which was noticed also in the present study using B250. ${ }^{27-29}$
Parameters obtained from the VEMP responses in this study can be compared with previous studies to confirm the robustness of the data. There are several studies using AC stimuli, but fewer presenting data from both AC and $\mathrm{BC}$ stimuli. Rosengren et al measured both $\mathrm{AC}$ and $\mathrm{BC}$ evoked cVEMP and oVEMP in 61 normal subjects, using a $\mathrm{B} 71$ bone conductor at the mastoid and with a stimulation frequency of $500 \mathrm{~Hz}$ instead of $250 \mathrm{~Hz} \cdot{ }^{30}$ As shown in Table 2, comparing the results from Rosengren et al 2011 with our results, there is generally a good resemblance between $\mathrm{AC}$ and $\mathrm{BC}$ results in terms of latencies and amplitudes for oVEMP and cVEMP. For BC stimuli, latencies were mainly the same but the VEMP amplitudes were a bit higher in the present study, possibly related to the difference in stimulation frequency, as $250 \mathrm{~Hz}$ is known to be more sensitive than $500 \mathrm{~Hz}$. One more difference, reported in the Rosengren study, was that $\mathrm{BC}$ oVEMP and cVEMP responses were obtained only in $65 \% / 62 \%$ of the 61 normal subjects. In a study by Fröhlich et al 2021 using B81 on 24 normal subjects at $500 \mathrm{~Hz}$, the oVEMP response rate was $83-92 \%$ on the mastoid and as low as $17-22 \%$ on the forehead, whereas in

Table 2 Comparison of oVEMP and cVEMP Parameters (n 10, pI5, pl3, n23) in Present and Other Studies for AC and BC Stimulation for Positive and/or Negative Polarity $\left( \pm\right.$ pol) of the Leading Cycle at the Mastoid $\left(F_{M}\right)$, Forehead $\left(F_{Z}\right)$ and/or Vertex $\left(F_{X}\right)$

\begin{tabular}{|c|c|c|c|c|c|c|c|}
\hline & \multicolumn{3}{|c|}{ oVEMP } & \multicolumn{3}{|c|}{ cVEMP } & \multirow[t]{2}{*}{ Study } \\
\hline & $\mathrm{n} 10 \mathrm{~ms}$ & pl5 ms & $\mathbf{p}-\mathbf{p} \boldsymbol{\mu V}$ & pl3 ms & $\mathrm{n} 23 \mathrm{~ms}$ & p-p corr & \\
\hline$A C$ & $9.7 \pm 1.2$ & $14.5 \pm 1.7$ & $4.6 \pm 3.6$ & $14.0 \pm 1.3$ & $22.9 \pm 1.6$ & $1.5 \pm 0.6$ & \multirow{4}{*}{$\begin{array}{c}\text { Present } \\
\text { AC: } 500 \mathrm{~Hz}, 4 \mathrm{~ms} \\
\text { BC: } 250 \mathrm{~Hz}, 4 \mathrm{~ms}\end{array}$} \\
\hline B250 F & $10.8 \pm 1.3$ & $15.0 \pm 2.0$ & $5.8 \pm 3.1$ & $14.0 \pm 1.7$ & $24.5 \pm 1.7$ & $3.0 \pm 2.8$ & \\
\hline B250 $F_{Z}(+p o l)$ & $12.0 \pm 1.2$ & $16.0 \pm 1.6$ & $5.4 \pm 3.0$ & $15.3 \pm 1.7$ & $23.8 \pm 1.9$ & $2.4 \pm 2.0$ & \\
\hline Minishaker $\mathrm{F}_{\mathrm{Z}}(+\mathrm{pol})$ & $10.5 \pm 2.3$ & $14.4 \pm 2.9$ & $6.6 \pm 3.3$ & $13.9 \pm 1.6$ & $23.6 \pm 1.3$ & $2.9 \pm 2.4$ & \\
\hline$A C$ & $9.3 \pm 0.5$ & $14.0 \pm 1.0$ & $4.5 \pm 2.3$ & $14.1 \pm 1.4$ & $23.5 \pm 2.4$ & $1.0 \pm 0.6$ & \multirow{4}{*}{$\begin{array}{c}\text { Fröhlich et al 202I. }{ }^{17} \\
\text { AC: } 500 \mathrm{~Hz}, 2 \mathrm{~ms} \\
\text { BC: } 500 \mathrm{~Hz}, 2 \mathrm{~ms} \\
\text { Right ear tested. }\end{array}$} \\
\hline B-8I FM (+pol) & $9.5 \pm 1.0$ & $14.6 \pm 1.0$ & $5.8 \pm 3.7$ & $14.5 \pm 1.6$ & $24.6 \pm 2.0$ & $1.3 \pm 0.5$ & \\
\hline B-8I F $F_{Z}(+p o l)$ & $12.0 \pm 0.7$ & $16.6 \pm 0.2$ & $1.5 \pm 0.7$ & - & - & - & \\
\hline Minishaker $\mathrm{F}_{\mathrm{Z}}(+\mathrm{pol})$ & $8.6 \pm 0.5$ & $12.9 \pm 1.1$ & $5.4 \pm 4.7$ & - & - & - & \\
\hline$A C$ & $9.9 \pm 1.0$ & $15.4 \pm 1.8$ & $3.8 \pm 3.1$ & $14.9 \pm 1.9$ & $22.5 \pm 2.2$ & $1.4 \pm 0.6$ & \multirow{2}{*}{$\begin{array}{l}\text { Rosengren et al } 201 \mathrm{l}^{30} \\
\text { AC: } 500 \mathrm{~Hz}, 2 \mathrm{~ms} \\
\text { BC: } 500 \mathrm{~Hz}, 4 \mathrm{~ms}\end{array}$} \\
\hline B-7I F $F_{M}( \pm$ pol $)$ & $10.9 \pm 1.7$ & $16.3 \pm 2.2$ & $2.9 \pm 2.4$ & $15.5 \pm 1.8$ & $24.1 \pm 2.5$ & $1.3 \pm 0.6$ & \\
\hline Minishaker $F_{M}(-p o l)$ & $13.4 \pm 1.5$ & $18.1 \pm 2.0$ & $19.3 \pm 13.0$ & - & - & - & \multirow{2}{*}{$\begin{array}{c}\text { Westin and Brantberg } 2014 .^{9} \\
\text { BC: } 125 \mathrm{~Hz}, 8 \mathrm{~ms}\end{array}$} \\
\hline Minishaker $F_{X}(+p o l)$ & $15.1 \pm 1.3$ & $19.4 \pm 1.2$ & $12.7 \pm 6.6$ & - & - & - & \\
\hline Minishaker $F_{X}(+p o l)$ & $14.3 \pm 2.4$ & $18.7 \pm 2.5$ & $10.0 \pm 6.2$ & - & - & - & 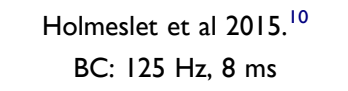 \\
\hline
\end{tabular}


the present study, BC oVEMP and cVEMP responses were found in all subjects at both positions using B250 at 250 Hz. ${ }^{17}$ Also, they reported that approximately $10 \mathrm{~dB}$ higher stimulation is required at the forehead in comparison with mastoid when stimulating at $500 \mathrm{~Hz}$, whereas in the present study at $250 \mathrm{~Hz}$ the average difference was $0.4 \mathrm{~dB}$ and not statistically significant. This shows that both the mastoid and $250 \mathrm{~Hz}$ stimulation are more efficient for evoking BC-VEMP responses than forehead position and $500 \mathrm{~Hz}$ stimulation.

Westin and Brantberg (2014) tested oVEMP on a group of normal subjects, both from the mastoid $F_{M}$ and vertex position $\mathrm{F}_{\mathrm{X}}$ (midline top of head), using the Minishaker and a single $125 \mathrm{~Hz}$ stimuli ( $8 \mathrm{~ms}$ ). Their latencies are delayed and their amplitudes are higher than in the present study, considering both the B250 at the mastoid and the Minishaker at the forehead. This might be explained by the lower stimulation frequency at $125 \mathrm{~Hz}$, where the stimulus is longer $(8 \mathrm{~ms})$ as compared to $250 \mathrm{~Hz}(4 \mathrm{~ms})$.

As $\mathrm{BC}$ stimulation at the midline of the skull is supposed to have some advantages as the both sides are stimulated at the same time, Holmeslet et al 2015 made an extensive study of oVEMP from vertex $\mathrm{F}_{\mathrm{X}}$ using the Minishaker at $125 \mathrm{~Hz}$ single-cycle stimulation on 50 controls. ${ }^{10}$ Similar to the findings by Westin and Brantberg (2014), their n10 and p15 latencies were longer and amplitudes higher than in the present study compared both with B250 at the mastoid, and the forehead position using the Minishaker, see the three last rows in Table 2. ${ }^{9}$ Also, in a study by Lin et al 2010, it was concluded that $\mathrm{F}_{\mathrm{X}}$ stimulation will give longer latencies and lower amplitude than $\mathrm{F}_{Z} \cdot{ }^{31}$ The reason for suggesting $\mathrm{F}_{\mathrm{X}}$ as stimuli site for VEMP, instead of $F_{Z}$ or $F_{M}$, is that it simplifies the attachment by balancing the Minishaker on top of the head, giving approximately $10 \mathrm{~N}$ static force due to its weight. However, when using the B250, only a steel spring headband is needed.

It should also be noted that the vertex $\mathrm{F}_{\mathrm{X}}$ stimuli in Holmeslet et al 2015 used a positive inward stimulation force (positive polarity), similar to the $F_{Z}$ polarity used in the present study and opposite to the $\mathrm{F}_{\mathrm{M}}$ polarity (negative). ${ }^{10}$ However, in several studies, it has been pointed out that at low frequencies, an inward deflection at the vertex will give an outward deflection at the mastoid, ie a negative polarity should be used at $\mathrm{F}_{\mathrm{M}} \cdot{ }^{9,13}$ This is yet another reason for suggesting that the B250 transducer at the mastoid should be moved to the other side when the vestibular organ on that side should be investigated - then the polarity will be correct in both cases. Also, the Eclipse can only use four electrodes simultaneously, which means that each side is already tested separately using the standard electrode montage. However, a systematic latency difference was noticed between the B250 and Minishaker at $F_{Z}$, where the response peaks are delayed even though the polarity of the stimulation signal was the same. This latency difference behavior was seen also in Fröhlich et al, 2021, see Table 2, and may be due to the ringing and ramping up effects of the variable reluctance type transducers in B250 and B81 as compared to the moving coil type transducer in the Minishaker which stimulates more rapidly. ${ }^{17}$

Among the parameters investigated in this study, the peak-to-peak amplitudes were found to have the largest inter-subject variation (but not intra-subject), while latencies and thresholds were more stable. This can be seen in Table 1, where the SDs are often larger than $50 \%$ of the mean values for the amplitudes, whereas for latencies, SDs are often lower than, or around $10 \%$, of the mean value. It was observed during the tests that slightly different electrode attachment from subject to subject could have a large effect on the amplitude variability rather than the underlying VEMP response itself, especially for cVEMP due to individual variations of the SCM tension. However, to avoid some of these differences, the electrodes were fixed on each subject while the source of stimulation was changed. Thereby, the electrode position remained the same throughout all measurements resulting in a more robust relative comparison within each subject.

\section{Conclusions}

Mastoid stimulation using the bone conductor B250 applied with a standard steel spring head band was compared with AC stimulation with an insert earphone and $\mathrm{BC}$ stimulation with a handheld Minishaker on the forehead.

It was found that VEMP using the B250 on the mastoid could be performed at a statistically significant lower hearing level (on average $41 \mathrm{~dB}$ for oVEMP and $35 \mathrm{~dB}$ for cVEMP) than AC stimulation using insert earphones.

There was not a statistically significant difference when comparing Minishaker stimulation at the forehead and B250 stimulation at the mastoid in terms of latencies and stimulus hearing level at threshold, neither for oVEMP nor for cVEMP. Comparing B250 at the mastoid with AC stimulation in terms of latencies, there was only a statistically significant difference for $n 10$ and $n 23$, which occurred $1.1 \mathrm{~ms}$ and $1.6 \mathrm{~ms}$ later with the B250.

The procedure is also easier to perform using the B250 as compared to the Minishaker BK4810. 
In the next phase, clinical studies on real patient groups will be investigated in order to show the clinical value and to determine sensitivity and specificity using BC-VEMP with the B250.

\section{Acknowledgment}

This study was supported by Swedish Innovations Agency (Vinnova), Kristina Stenborg foundation, The Swedish Association of Hard of Hearing People (HRF) and Ortofon A/S Denmark.

\section{Disclosure}

The co-author Bo Håkansson holds patents regarding the transducer principle of $\mathrm{B} 250$ and report non-financial support from Ortofon A/S, non-financial support from Interacoustics, during the conduct of the study. The authors report no other conflicts of interest in this work.

\section{References}

1. Minor LB, Solomon D, Zinreich JS, Zee DS. Sound-and/or pressure-induced vertigo due to bone dehiscence of the superior semicircular canal. Arch Otolaryngol Head Neck Surg. 1998;124 (3):249-258. doi:10.1001/archotol.124.3.249

2. Murofushi T, Matsuzaki M, Mizuno M. Vestibular evoked myogenic potentials in patients with acoustic neuromas. Arch Otolaryngol Head Neck Surg. 1998;124(5):509-512. doi:10.1001/archotol.124.5.509

3. de Waele C, Huy PT, Diard JP, Freyss G, Vidal PP. Saccular dysfunction in Meniere's disease. Am J Otol. 1999;20(2):223-232.

4. Rosengren SM, Colebatch JG, Young AS, Govender S, Welgampola MS. VEMP in practice: methods, pitfalls and clinical applications. Clin Neurophysiol Pract. 2019;4:47-68. doi:10.1016/j. cnp.2019.01.005

5. Deepak DT, Bhat JS, Kumar K. Ocular vestibular evoked myogenic potential using different test stimuli. ISRN Otolaryngol. 2013;2013:1-4. doi:10.1155/2013/161937

6. Colebatch JG, Halmagyi GM. Vestibular evoked potentials in human neck muscles before and after unilateral vestibular deafferentation. Neurology. 1992;42(8):1635. doi:10.1212/WNL.42.8.1635

7. Halmagyi GM, Yavor RA, Colebatch JG. Tapping the head activates the vestibular system: a new use for the clinical reflex hammer. Neurology. 1995;45:1927-1929. doi:10.1212/WNL.45.10.1927

8. Iwasaki S, Chihara Y, Smulders YE, et al. The role of the superior vestibular nerve in generating ocular vestibular-evoked myogenic potentials to bone conducted vibration at Fz. Clin Neurophysiol. 2009;120(3):588-593. doi:10.1016/j.clinph.2008.12.036

9. Westin M, Brantberg K. Mastoid and vertex low-frequency vibration induced oVEMP in relation to medially directed acceleration of the labyrinth. J Clin Neurophysiol. 2014;125:615-620. doi:10.1016/j. clinph.2013.08.019

10. Holmeslet B, Foss OA, Bugten V, Brantberg K. Ocular vestibular-evoked myogenic potentials (oVEMPs) in response to bone-conducted vertex vibration. $J$ Clin Neurophysiol. 2015;126:608-613. doi:10.1016/j.clinph.2014.06.027

11. Krause E, Mayerhofer A, Gürkov R, et al. Effects of acoustic stimuli used for vestibular evoked myogenic potential studies on the cochlear function. Otol Neurotol. 2013;34:1186-1192. doi:10.1097/ MAO.0b013e31829ce7b4
12. Mattingly JK, Portnuff CD, Hondorp BM, Cass SP. Sudden bilateral hearing loss after cervical and oVEMP. Otol Neurotol. 2015;36:961-964. doi:10.1097/MAO.0000000000000764

13. Håkansson B, Jansson KJF, Tengstrand T, et al. VEMP using a new low-frequency bone conduction transducer. Med Devices (Auckl). 2018;11:301-312. doi:10.2147/MDER.S171369

14. Håkansson B. The balanced electromagnetic separation transducer: a new bone conduction transducer. $J$ Acoust Soc Am. 2003;113:818-825. doi:10.1121/1.1536633

15. Fredén Jansson K-J, Håkansson B, Johannsen L, Tengstrand T. Electro-acoustic performance of the new bone vibrator Radioear B81: a comparison with the conventional Radioear B71. Int J Audiol. 2015;54:334-340. doi:10.3109/14992027.2014.980521

16. Clinard CG, Piker EG, Thorne AP, et al. Maximum output and low-frequency limitations of B71 and B81 clinical bone vibrators: implications for vestibular evoked potentials. Ear Hear. 2020;41 (4):847-854. doi:10.1097/AUD.0000000000000808

17. Fröhlich L, Wilke M, Plontke SK, Rahne T. Influence of bone conduction transducer type and placement on ocular and cervical vestibular evoked myogenic potentials. Sci Rep. 2021;11(1):1-8. Research Square. doi:10.21203/rs.3.rs-156788/v1

18. Handzel O, Himmelfarb M. The occlusion effect in bone conducted cVEMP. J Vestib Res. 2018;28(3-4):305-309. doi:10.3233/VES180639

19. Murofushi T, Ohki M, Tsubota M. Effects of external auditory meatus occlusion on ocular vestibular evoked myogenic potentials induced by bone conducted sound. Front Neurol. 2021;12. doi:10.3389/ fneur.2021.659820

20. Stenfelt S, Zeitooni M. Binaural hearing ability with mastoid applied bilateral bone conduction stimulation in normal hearing subjects. J Acoust Soc Am. 2013;134:481-493. doi:10.1121/ 1.4807637

21. Welgampola MS, Rosengren SM, Halmagyi GM, Colebatch JG. Vestibular activation by bone conducted sound. J Neurol Neurosurg Psychiatry. 2003;74:771-778. doi:10.1136/jnnp.74.6.771

22. Chihara Y, Iwasaki S, Fujimoto $C$, Ushio $M$, Yamasoba $T$, Murofushi T. Frequency tuning properties of ocular vestibular evoked myogenic potentials. NeuroReport. 2009;20:1491-1495. doi:10.1097/ WNR.0b013e3283329b4a

23. Dennis DL, Govender S, Colebatch JG. Properties of cervical and ocular vestibular evoked myogenic potentials (cVEMPs and oVEMPs) evoked by $500 \mathrm{~Hz}$ and $100 \mathrm{~Hz}$ bone vibration at the mastoid. J Clin Neurophysiol. 2016;127:848-857. doi:10.1016/j.clinph.2015.06.027

24. Verrecchia L, Westin M, Duan M, Brantberg K. Ocular vestibular evoked myogenic potentials to vertex low frequency vibration as a diagnostic test for superior canal dehiscence. J Clin Neurophysiol. 2016;127:2134-2139. doi:10.1016/j.clinph.2016.01.001

25. McNerney KM, Burkard RF. The vestibular evoked myo-genic potential (VEMP): air- versus bone-conducted stimuli. Ear Hear. 2011;32:e6-e15. doi:10.1097/AUD.0b013e3182280299

26. Plontke S, Zenner HP. Current aspects of hearing loss from occupational and leisure noise. GMS Curr Top Otorhinolaryngol Head Neck Surg. 2004;3:Doc06.

27. Curthoys IS, Kim J, McPhedran SK, Camp AJ. Bone conducted vibration selectively activates irregular primary otolithic vestibular neurons in the guinea pig. Exp Brain Res. 2006;175:256-267. doi:10.1007/s00221-006-0544-1

28. Curthoys IS, Manzari L. Otolithic disease: clinical features and the role of vestibular evoked myogenic potentials. Semin Neurol. 2013;33(3):231-237. Thieme Medical Publishers. doi:10.1055/ s-0033-1354595

29. Curthoys IS, Vulovic V, Burgess AM, Sokolic L, Goonetilleke SC. The response of guinea pig primary utricular and saccular irregular neurons to bone-conducted vibration (BCV) and air-conducted sound (ACS). Hear Res. 2016;331:131-143. doi:10.1016/j. heares.2015.10.019 
30. Rosengren SM, Govender S, Colebatch JG. Ocular and cervical vestibular evoked myogenic potentials produced by air-and bone-conducted stimuli: comparative properties and effects of age. $J \quad$ Clin Neurophysiol. 2011;122:2282-2289. doi:10.1016/j. clinph.2011.04.001
31. Lin CM, Wang SJ, Young YH. Ocular vestibular evoked myogenic potentials via bone-conducted vibrations applied to various midsagittal cranial sites. Otol Neurotol. 2010;31(1):157-161. doi:10.1097/ MAO.0b013e3181c2a0e1

\section{Publish your work in this journal}

Medical Devices: Evidence and Research is an international, peerreviewed, open access journal that focuses on the evidence, technology, research, and expert opinion supporting the use and application of medical devices in the diagnosis, monitoring, treatment and management of clinical conditions and physiological processes. The identification of novel devices and optimal use of existing devices which will lead to improved clinical outcomes and more effective patient management and safety is a key feature of the journal. The manuscript management system is completely online and includes a very quick and fair peer-review system. Visit http:// www.dovepress.com/testimonials.php to read real quotes from published authors. 